\title{
How Parents Can Reduce the Negative Impact of Media Devices on Young Children? An Overview of Preliminary Guidance for Parents
}

\author{
Nasriah $^{1 *}$, Santa Murni A. Situmorang ${ }^{2}$, Elvi Mailani $^{3}$, Srinahyanti ${ }^{4}$ \\ \{*santamurniasih@gmail.com $\}$ \\ Faculty of Education, Universitas Negeri Medan, Indonesia ${ }^{1}$
}

\begin{abstract}
Very young children recently have engaged with media devices such as TV set, computer and mobile devices. Playing with all devices is the most attractive activity than interacting with their environment. They look like a quickly learners regarding devices use than their parents and the media devices used by young children is rapidly increases year by year. Many researchers agree that media devices children use have an impact both positive and negative on development and learning. Beside the all benefit of devices for children, parents must also pay attention with the negative impact possibility in devices children use. Therefore, parents play very important role in their children. Parents should be able to encourage their children of avoiding an inappropriate media device use in order to reduce negative impact that can affect their growth and development. The aim of this article is to review some literature about negative impact of young children media device use, suggest preliminary guidance for parents and recommend the future research need.
\end{abstract}

Keywords: Media devices, young children, negative impact, parent's role

\section{Introduction}

In the $21^{\text {st }}$ century today, we are entering a digital revolution era called the Industrial Revolution 4.0. The biggest challenge in this century is technology acceleration. Martec's Law by Scott Brinker explained that technology changes exponentially but organizations change logarithmically which means technology is changing faster than organizations can absorbs change. We will feel its incredible benefit in our lives such as Automation, Big Data, Internet of Thing and Artificial Intelligence so humans must quickly adapt, before being colonized by the technology they make themselves.

Ideally, technology like digital media is essentially created to ease human work become more effective and efficient. But in the reality, it is also influencing all aspects of our lives. Many studies that focus on both the positive and negative impacts of technology, especially for young children. Teachers, parents, health providers, and child development expert all agree that technology children use can have an impact both positive and negative on learning and development [1]. McManis and Gunnewig focus on positive impact of technology for young learners. They have discussed regarding educational technology in three areas: developmental appropriateness, supported implementation, and classroom and curriculum integration. If these area are considered together, it can strengthen the potential of technology to facilitate meaningful learning and development for early learners [2]. On the other hands, most studies focus on negative impact of technology for young children. American Academic 
of Pediatric indicate that there are some risks of using device like disruption on sleep, attention and learning. Lack of knowledge or information by parents might be one of the causes. Based on developmental theory and educational experts, young children period is the most active period of their lifetime. This is a critical and very important period which all developmental aspects were rapidly increased. Child interaction with the physical and social environment is a very important factor in this period. Therefore in this article, we will discuss and concern about of the negative impact of technology on young children and the role of parents in this case [3].

\section{Literature Review}

\subsection{Negative Impact of Technology For Young Children}

Recently the number of children who engage in technology is rapidly increasing every year. The phenomenon calls us to be wisely respond to it. Technology refers to devices such as television, computers and smartphone and to the products that are played or created on these devices such as DVDs, program channels, games and sosial media. Behind the incredible features and benefits, remain to be aware of all the negative impact possibility.

According to Common Sense Media's survey research in 2013, the percent of children among 0 to 8 years old used a mobil device is increase rapidly from $52 \%$ to $75 \%$ in just two years. They found that the time spent with total screen media in average is about one hour a day before age 2, two hours a day at age 2-4 and more than two hours at age 5-8. The most ownership of device is smarthphone an tablet, the most popular activity is playing games, watching tv, videos and using apps [1].

Furthermore, American Academic of Pedriatics adapt the Common Sense Media's survey in 2014, found that almost all children (96\%) used mobile device, and most children using device before age 1 , at age 2 , most children were using mobil devices on a daily basis and spending comparable screen time on television and the mobil device, at age 3-4, children were able to use mobile devices without help, and 1 in 3 were media multitasking and 3 out of 4 children had their own mobil device by age 4 . The most device in the home is TV, Tablet and video games console, the most popular ownership of device is Tablet and the most favorit activity is watching TV, Video, use Applications (YouTube and Netflix) and play games.The study implies that ownership of device tend to be free for access on their demand which means parents might be do not know what content that their explore whether it is educative or not [4]. Furthermore, according to several studies, these are some negative impact of using device on young children:

a. Risk of sleep disturbance. The presence of a TV, computer or mobile device in the bedroom, long duration of viewing, , light emitted from devices, violent content and daytime screen was associated with delayed bedtime and sleep deficiency [3] and [5].

b. Obesity.There are association between using more than 2 hours per day of TV viewing and obesity, because of lack of physical movement [3].

c. Risk of exposure to inaccurate, inappropriate or unsafe content [3].

d. Depression [3].

e. Risk of addiction [3].

f. Radiation risk. Blue light emitted from devices might cause the radiation risk for eye and brain [3]. 
g. Poor are sight later. Radiaton effect and time duration of device use in early age can cause poor sight for kids [6].

h. Lack of sosial skill. Device exposure negatively can potentially displace child interaction and other enriching activities. In other hand, before age 2, they are still in sensorimotor stage which require hands-on exploration and social interaction with trusted adult like parent or caregivers for successful maturation and also support development of motor skills [7].

i. Aggressive behavior. [3] There are strong association between violent media content and child aggressive behavior.

j. Difficulty learning. When Infant and young toddler watched videos, they have not been able to transfer knowledge from a 2-dimensional platform to a 3-dimensional world because of lack of symbolic thinking, immature attentional controls and the memory flexibility required.

k. Risk of attention [8]. Time duration in front of devices can be predictor of attention disorder or interference in attention [9].

\subsection{The Role of Parents}

Family is the first environment for children to get education, especially young children who need a confortable attachment from their parents or caregivers. Parents play a very important role in encouraging of child growth and development and currently it is a big challenge for them because young children are growing up in the digital era. Many studies have found about how parents use media with or around children and implement family rules regarding media and many researches indicate that negative impact of technology for young children is strongly influenced by their treatments. Oftenly, the most reason why parents allow their children engage with media device are to calm them down or keep them quiet or keep them busy while they are working or when their children had temper tantrum [9]. In other hand, parents feel than children need to learn media devices because today' children live in digital world which means their future is related to digital technology.

According to some researchers' studies, here are five preliminary guidelines for parents related to media devices children use:

\subsection{Parents Is A Role Model for Their Children}

Parents should understand their own roles in modeling appropriate media use because children are eminent imitator [3]. Based on child developmental theory, it is recognized that children are active learner and expert in constructing their own knowledge. Children learn through the senses and movements as well as of object in their environment. The interaction with the physical and social environment is the most important thing to do in young children period [10]

\subsection{Limiting Young Children's Media Device Viewing Time}

Pay attention to how much time children spend using all screen media. Parents should to reduce children's devices-viewing time and can balance between media device time and traditional developmental activities time [11]. American Academic of Pediatrics recommended parents only allow their child over age 2 to engaged with all devices no more than 1-2 hours a day and to adapt a healthy Family Media Use Plan from www.healthychildren.org/MediaUsePlan, in order to minimize unhealthy habits and behaviors such as sleep deficiency and tantrum [3] and [8]. Parents should have some potential strategies to limit devices viewing. Parents should encourage a bedtime routin than includes calming 
activities and avoids electronic media use [5]. For example, here are some strategies to limit television viewing that is recommended by American Academic of Pediatrics [8]:

a. Turning off the television when no one is actively watching.

b. Turning off the television during meals and no television in eating areas.

c. No television in children's bedrooms.

d. Eliminate background television.

e. Identify nonscreen, in-home activities that are pleasuable to children.

\subsection{The Using of Media Devices Must Support Young Children's Growth and Development}

Parents should be able to choose a developmentally appropriate media device and the content for young children. Parents should collaborate with the teacher in using media devices in a developmentally appropriate with young children. Parents may use the Haugland Developmental Software Scala to evaluate available media divices or application for young children. Furthermore, parents always up date their own knowledge about the recent developmentally appropriate activities and alternative strategies for teaching young children [12].

\subsection{Limiting Young Children's Media Device Viewing Time}

Parents should discuss media content with their children and pay particular attention to content involving violence, sex, substance use, body image, and the other harm content [11]. Furthermore, parents shoud try app first then play it with the child about it afterward to see what they is learning [7].

2.7. The Using of Digital Devices and Traditional Development Media Must Be Balanced

Parents should frequently distract the electronic media usage by traditional developmental media into the $21^{\text {st }}$ century child's life [13]. Children shoud have given more experiences to use concrete materials in the learning process and to connect with social interaction. Parentchild interactions are important opportunity for emotional connection and are needed for young children development of language, cognition, social skills and emotion regulation [3]. Based on Piaget's theory that young children at age 2-7 years are in the pre-operational stage where there is a rapidly increase in symbolic activities. Sociodramatic play or pretend play is one of developmental appropriate for young children in this stage [3].

\section{Result and Discussion}

This article focuses on describing the negative impact of using deviced based on literature from American Research. How about young children in Indonesia? We must pay attention to similar phenomenon regarding media devices use by young children in Indonesia. Therefore, it might be good to adapt American Academy of Pedriatrics survey to found whether the result show the similar tend or not. 


\section{Conclusion}

Young children today are growing up in digital era. They would rather engage with media devices than interact with their environment or other activities. Based on some research found that negative impact of using all devices by young children can influence their health, development and learning. The using devices is associated to sleep disturbance, attention disorder, lack of sosial skills, difficulty learning etc. Therefore, parents play very important role to encourage their children regarding media devices use. Parents should be able to limit the device viewing, control the appropriate content, upgrade knowledge about best strategies to balance media device use and traditional developmental activities to encourage their growth and development. Finally, future research needs to compare to the phenomenon in young children in Indonesia regarding tends of using media devices and whether it indicates negative impact or not.

\section{References}

[1] S. Brinker, "Martec's law: Technology changes exponentially, organizations change logarithmically." 2013.

[2] C. S. Media, "Zero to eight: Children's media use in America 2013." Author San Francisco, CA, 2013.

[3] L. D. McManis and S. B. Gunnewig, "Finding the education in educational technology with early learners," Young Child., vol. 67, no. 3, pp. 14-24, 2012.

[4] Y. L. R. Chassiakos, J. Radesky, D. Christakis, M. A. Moreno, and C. Cross, "Children and adolescents and digital media," Pediatrics, vol. 138, no. 5, p. e20162593, 2016.

[5] H. K. Kabali et al., "Exposure and use of mobile media devices by young children," Pediatrics, p. peds-2015, 2015.

[6] L. Hale and S. Guan, "Screen time and sleep among school-aged children and adolescents: a systematic literature review," Sleep Med. Rev., vol. 21, pp. 50-58, 2015.

[7] M. Sarwar and T. R. Soomro, "Impact of Smartphone's on Society," Eur. J. Sci. Res., vol. 98, no. 2, pp. 216-226, 2013.

[8] S. M. Coyne et al., "Parenting and digital media," Pediatrics, vol. 140, no. Supplement 2, pp. S112-S116, 2017.

[9] S. Keating, "A study on the impact of electronic media, particularly television and computer consoles, upon traditional childhood play and certain aspects of psychosocial development amongst children," Int. J. Cross-Disciplinary Subj. Educ., vol. 2, no. 1, pp. 294-303, 2011.

[10] J. W. Santrock, "Life-Span Development: Perkembangan Masa Hidup (edisi kelima).(Penerj. Achmad Chusairi, Juda Damanik; Ed. Herman Sinaga, Yati Sumiharti)," Erlangga. Jakarta, 2002.

[11] J. S. Radesky, J. Schumacher, and B. Zuckerman, "Mobile and interactive media use by young children: the good, the bad, and the unknown," Pediatrics, vol. 135, no. 1, pp. 1-3, 2015.

[12] L. Plowman and J. McPake, "Seven myths about young children and technology," Child. Educ., vol. 89, no. 1, pp. 27-33, 2013.

[13] A. B. Jordan, J. C. Hersey, J. A. McDivitt, and C. D. Heitzler, "Reducing Children9s Television-Viewing Time: A Qualitative Study of Parents and Their Children," Pediatrics, vol. 118, no. 5, pp. e1303-e1310, 2006. 